\title{
Optimasisasi Mobile Ad-Hoc Network dengan Algoritma Particle Swarm Optimization
}

\author{
Alon Jala Tirta Segara*, Aditiya Wijayanto \\ Fakultas Informatika, Rekayasa Perangkat Lunak, Institut Teknologi Telkom Purwokerto, Jawa Tengah, Indonesia \\ Email: 1,*alon@ittelkom-pwt.ac.id, ${ }^{2}$ aditya.wijayanto@ittelkom-pwt.ac.id, \\ Email Penulis Korespondensi: alon@ittelkom-pwt.ac.id
}

\begin{abstract}
Abstrak-Pada era digital ini perkembangan teknologi terjadi sebuah evolusi pada teknologi media, sebut saja new media atau orang juga sering menyebutnya media online atau orang lebih akrab lagi menyebutnya dengan istilah internet, media ini tentunya sudah tidak asing lagi di telinga. Pengiriman data untuk melakukan komunikasi dapat terhambat hal ini terjadi karena ada nya nganguan satelit yang di sebabkan oleh cuaca atau pun karena ada nya kerusakan pada satelit dan menimbulkan delay pada pengiriman data yang dapat mengakibatkan terlambatnya masuk nya informasi. Maka dari penelitian ini ingin mengimplementasikan mobile ad-hoc network (manet) dan melakukan evaluasi dari hasil metode manet tersebut dengan mengetahui hasil end to end delay dan packet delivery ratio Normalized routing load untuk mengetahui yang ada. Metode penelitian menggunakan metode simulasi dan evaluasi model routing menggunakan sebagai. Evaluasi yang diprioritaskan pada pengunaan parameter hitung yang ada untuk menguji protokol AOMDV lalu kami mengunakan algoritma PSO untuk dapat melakukan optimasasi nilai parameter hitung yang ada. Dalam penilitian ini telah dilakukan dengan mengunakan 2 skenario dengan masing-masing skenario mempunyai jumlah node yaitu 30 dan 50 lalu dengan luas area $1000 \mathrm{~m} \times 1000 \mathrm{~m}$ dan juga kecepatan pengiriman data 200/kbps dan kecepatan 200 pada setiap skenario. Setelah melakukan simulasi dan melihat nilainilai perbandingan yang ada maka kami peroleh suatu kesimpulan mengenai Dari hasil uji coba parameter di atas didapatkan nilai rata-rata PDR pada node 50 95,1 dan node 30 81,5\% , nilai NRL pada node 50 51,4\% dan node $3012,7 \%$. Sedangkan pada nilai optimasisasi dengan PSO setiap parameter terjadi pada kenaikan yang signifikan pada nilai parameter PDR dan NRL sedangkan untuk nilai Avaerage delay terjadi penurunan pada setiap nilai simulasi.
\end{abstract}

Kata Kunci: AOMDV, Mobile Ad-Hoc Network; PSO

\begin{abstract}
In this digital era the development of technology occurs an evolution in media technology, let's call it new media or people also often call it online media or people are more familiarly called it the internet, this media is certainly familiar to the ears. The delivery of data for communication can be hampered because of the lack of satellites caused by the weather or because of damage to the satellites and delays in the delivery of data that may result in late entry of information. Therefore we want to implement mobile ad-hoc network (manet) and evaluate the results of the manet method by knowing the results of end to end delay and packet delivery ratio Normalized routing load to know the existing. The research method uses simulation method and evaluation of routing model using Network Simulator. Evaluation is prioritized on the use of existing calculated parameters to test the AOMDV protocol and then we use the PSO algorithm to be able to optimize the value of existing calculated parameters. In this study has been done by using 2 scenarios with each scenario has a number of nodes namely 30 and 50 ago with an area of $1000 \mathrm{~m} \times 1000 \mathrm{~m}$ and also data delivery speed of 200/kbps and speed of 200 in each scenario. After doing the simulation and looking at the existing comparison values, we came to a conclusion about the results of the parameter trial above obtained the average value of PDR on nodes 5095.1 and nodes $3081.5 \%$, NRL values on nodes $5051.4 \%$ and nodes $3012.7 \%$. While in optimization value with PSO each parameter occurs in a significant increase in PDR and NRL parameter value while for Avaerage delay value there is a decrease in each simulation value.
\end{abstract}

Keywords: AOMDV, Mobile Ad-Hoc Network; PSO

\section{PENDAHULUAN}

MANET adalah sebuah jaringan tanpa kabel dari mobile node yang tidak memiliki router tetap. node dalam jaringan ini berfungsi juga sebagai router yang bertanggung jawab untuk mencari dan menangani route ke setiap node di dalam jaringan. router bergerak bebas secara random, dengan demikian topologi jaringan tanpa kabel mungkin dapat berubah dengan cepat dan tidak dapat diprediksi. Untuk mengatasi pergerakan ini diperlukan suatu protokol ruting yang digunakan untuk membangun rute antar node agar setiap node dalam jaringan dapat melakukan komunikasi di dalam jaringan[1].

MANET, node berfungsi juga sebagai router yang bertanggung jawab untuk mencari dan menangani rute ke setiap node di dalam jaringan. Pergerakan setiap node berpengaruh pada rute transmisi dan topologi jaringan yang dapat menyebabkan kegagalan jalur rute[2]. Hal ini mempengaruhi komunikasi antar node dan juga kualitas pengiriman data. Di era digital ini perkembangan teknologi terjadi sebuah evolusi pada teknologi media, sebut saja new media atau orang juga sering menyebutnya media online atau orang lebih akrab lagi menyebutnya dengan istilah internet, media ini tentunya sudah tidak asing lagi di telinga. Media ini juga disebut-sebut sebagai media yang sampai saat ini belum ada yang menandingi pertumbuhan jumlah penggunanya. Di negara maju, new media mengalahkan berbagai media yang sebelumnya telah dijadikan sumber referensi dalam mendapatkan sebuah informasi.Istilah new media muncul pada akhir abad 20, istilah ini digunakan untuk menyebut media jenis baru yang menggabungkan antara media konvensional dengan media internet. Dalam kurun waktu beberapa tahun belakangan ini new media diramaikan oleh fenomena munculnya situs jejaring sosial, situs ini menyediakan tempat didunia maya untuk membangun suatu ko munitas jejaring pertemanan yang dapat diakses oleh semua orang di seluruh dunia. Perkembangan teknologi informasi yang terjadi memunculkan istilah E-Commerce yaitu proses 
pembelian dan penjualan produk,jasa dan informasi yang dilakukan secara elektronik dengan menggunakan jaringan komputer dan jaringan yang digunakan adalah jaringan internet.Protokol routing memainkan peran penting dalam MANET untuk menentukan rute pengiriminan paket dan memastikan bahwa paket-paket akan dikirim ke tujuan yang benar. Protokol-protokol ini diklasifikasikan sebagai berikut: proaktif, reaktif, dan hibrid. Diantara protokol tersebut, kategori protokol reaktif banyak digunakan karena bisa menentukan rute setiap kali diperlukan.

Protokol[3] AOMDV dan juga AODV adalah protokol routing reaktif yang dibuat khusus untuk jaringan MANET[2]. Kedua protokol menawarkan adaptasi yang cepat terhadap kondisi link yang dinamis, proses yang rendah, rendahnya penggunaan jaringan dan menentukan pilihan rute ke tujuan dalam jaringan ad hoc. AOMDV memungkinkan node mobile untuk mendapatkan rute ke tujuan baru dengan cepat.

Berdasarkan penelitian terdahulu pada formasi burung nilai end to end delay protokol routing AOMDV lebih besar jika dibandingkan dengan protokol routing AODV seiring dengan bertambahnya jumlah node yang digunakan dalam simulasi. Hal ini dikarenakan routing DSR mengalami proses pencarian jalur lebih lama dan lebih panjang dibanding AODV[4]. Hal ini mengakibatkan rata-rata delay pada routing DSR lebih lama karena banyaknya hop yang ditempuh dari node sumber ke node tujuan. Routing AOMDV menanggapi request pengiriman pertama yang diterima dan mengabaikan request selanjutnya dari sumber node yang berbeda. Hal ini dapat mengurangi kemacetan dalam pencarian jalur menuju node tujuan sehingga dapat meminimalisasi delay. Sedangkan protokol routing DSR menanggapi semua RREQ yang datang, sehingga kemacetan tidak dapat terhindarkan yang menyebabkan delay semakin besar.pada penilitan juga akan mengunakan PSO untuk mendapatkan nilai optimal pada parameter uji yang di pakai [5].

\section{METODOLOGI PENELITIAN}

Penelitian ini adalah merupakan simulasi dari pengiriman data menggunakan protocol routing AOMDV. Menggunakan 2 jenis sumber trafik dengan mobilitas node perbeda data untuk mengukur model sumber trafik mana yang memiliki End to end delay dan, Packet delivery dan juga ukuran Normalized routing load yang ada [6].

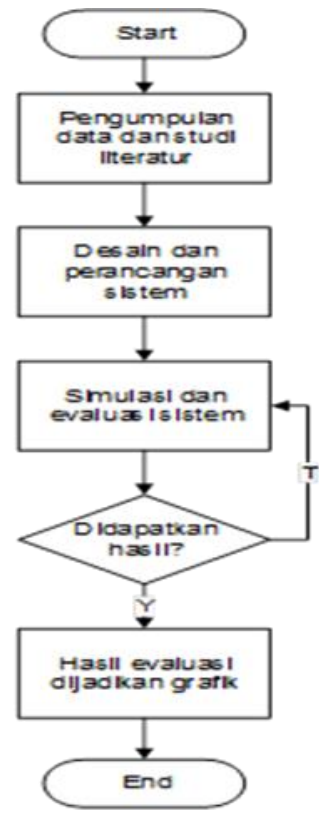

Gambar 1. Alur Rancangan Penelitian Keterangan.

Spesifikasi Sistem, adapun pada penelitan ini Seperti yang tertera pada dibawah ini. Jaringan berjalan dalam sistem operasi linux ubuntu 14.04. Dalam hal ini sistem operasi tersebut menggunakan lisensi open-source, dimana dalam lisensi open-source tersebut mengizinkan setiap pengguna dapat mengakses kode sumber kompilasi yang nantinya berpengaruh pada aplikasi-aplikasi pendukung (network simulator) .

Dengan akses terhadap kode sumber ini, dapat dilakukan pengembangan, perbaikan, maupun modifikasi terhadap aplikasi-aplikasi pendukung tersebut. Hal ini berlawanan dengan perangkat lunak yang berlisensi terbatas, dimana hanya hasil kompilasi dari kode. proses installasi aplikasi, dari aplikasi network simulator (NS) [7]. Dimana aplikasi network simulator menggunakan versi 2 dengan bentuk terpadu (all-in-one) komponenkomponen utama pendukung NS-2 telah dipaketkan dalam sebuah sebuah file. Untuk aplikasi network animator nantinya digunakan sebagai visualisasi simulasi jaringan dan perjalanan paket pada simulasi tersebut.

Ad-Hoc On-demand Multipath Distance Vector Routing (AOMDV). merupakan salah satu protokol routing reaktif yang paling banyak diteliti. AOMDV dirancang untuk jaringan ad hoc mobile[8]. AOMDV menawarkan adaptasi 
yang cepat terhadap kondisi link yang dinamis, proses yang rendah, rendahnya penggunaan jaringan dan menentukan pilihan rute ke tujuan dalam jaringan ad hoc. AOMDV AODV memungkinkan node mobile untuk mendapatkan rute ke tujuan baru dengan cepat[7]. Lalu kami disini juga mengunakan Particle Swarm Optimization agar kami mendapatakan optimasisasi yg optimal untuk dapat mengetahui nilai parameter yang kami ujikan secara optimal. Rancangan jaringan.Berdasarkan studi literature akan dibuat deskripsi umum mengenai rancangan uji coba yang akan dibuat serta dilakukan analisa kebutuhan pendeteksian. Selain itu juga dilakukan evaluasi dari uji coba yang akan dibuat sehingga akan dihasilkan suatu analisa kinerja protokol routing AOMDV sesuai dengan yang diharapkan. Tahapan simulasi yang dikembangkan akan disimulasikan dan dievaluasi menggunakan Network Simulator 2 (NS2), pengujian dilakukan dengan membandingkan beberapa kondisi dimana difokuskan pada model mobilitas node yang di[6] asumsikan Dalam simulasi ini juga kami memakai jenis trafik yang yaitu untuk melakukan berbandingan. Disini juga kami mengunakan luas area yang sama dan juga jumlah node yang berbeda dan kami menambahkan alogritma Particle Swarm Optimization untuk menetukan nilai optimal dalam skenario test yang kami ujikan.

Tabel 1. Spesifikasi sistem

\begin{tabular}{ll}
\hline Alat & Spesifikasi \\
\hline Simulator & NS 2.34 \\
MAC type & 802.11 \\
Waktu simulasi & 200 detik \\
Tipe frekuensi & VHF \\
Protokol routing & AOMDV \\
Area simulasi & $1000 \mathrm{~m} \times 1000 \mathrm{~m}$ \\
Tipe traffic & CBR \\
Jumlah node & $30 / 50$ \\
Model propagasi & Two ray \\
Ukuran paket & 200 bytes/packet \\
\hline
\end{tabular}

Rancangan Analisa Pembuktian, setelah diketahui bagaimana karakteristik dari model mobilitas yang digunakan yaitu random waypoint model dengan manhattan mobility model. Maka beberapa hal yang dianalisa untuk pembutian dalam penelitian ini dari kondisi model mobilitas yang bandingkan adalah dengan beberapa parameter. Parameter yang digunakan antara lain dua parameter, yaitu parameter packet delivery ratio dan end to end delay[9].

Packet Delivery Ratio adalah rasio antara banyaknya paket yang diterima oleh tujuan dengan banyaknya paket yang dikirim oleh sumber. Dimana dalam parameter in menggunakan rumus :

$$
\text { PDR }=\frac{\text { Number of Packet Reciever }}{\text { Number of Packet Trasmit }} \times 100
$$

Keterangan :

$\mathrm{PR}=$ paket yang diterima,

$\mathrm{PT}=$ paket yang dikirim

Dimana untuk menentukan parameter Packet Delivery Ratio dengan cara dari paket yang telah diterima dibagi dengan paket awal yang dikirim kemudian dikali dengan 100. Dari rumus tersebut dapat dilihat rasio pengiriman paket yang akan berjalan pada program nanti[9].

End to end delay adalah rata - rata waktu yang dibutuhkan oleh paket data untuk tiba ditempat tujuan yang mana mencakup keterlambatan yang disebabkan oleh penemuan rute dan antrian transmisi paket data[10]. Dimana dalam parameter ini menggunakan rumus :

$$
\text { End to end delay }=\text { Receive Time }- \text { Sent Time }
$$

Keterangan :

Receive Time $=$ waktu di terima

Sent Time= waktu pengiriman

Dimana untuk menentukan parameter End to End Delay dengan menambahkan jumlah node yang ada, jika node sudah ditambahkan maka akan terjadi delay, dimana dilakukan dengan mengirimkan pesan RREQ dalam jumlah node yang banyak, kemudian setelah dilakukan pengiriman maka akan mendapatkan balasan dari RREP, dimana RREP akan membalas pesan dari RREQ sesuai dengan jumlah node yang diminta[11], jika node yang diminta sedikit maka proses untuk membalas akan cepat, dan jika node yang diminta banyak maka proses untuk membalas juga akan lama, dari proses itulah bisa terjadi delay dalam node[11].

Normalized routing load merupakan rasio antara jumlah paket routing dengan paket data yang berhasil dikirim. Nilai parameter ini akan di peroleh dengan menggunakan script AWK[12]. 


$$
\text { Normalized Routing Load }=\frac{\text { Number of Routing Packets }}{\text { Number of Packets Received }}
$$

Particel swarm optimization Particle Swarm Optimization adalah teknik optimasi dengan cara menghitung secara terus menerus calon solusi dengan menggunakan suatu acuan kualitas. Algoritma ini mengoptimasi permasalahan dengan cara menggerakan partikel / calon solusi di dalam ruang permasalahan menggunakan fungsi tertentu untuk posisi dan kecepatan dari partikel[10].

Pembuatan Node Langkah selanjutnya setelah pengaturan node adalah pembuatan node itu sendiri, berikut script yang digunakan.

Pergerakan node merupakan pergerakan dari node pada saat simulasi dijalankan. Untuk penilitian in pergerakan node yang digunakan yaitu rand om waypoint model dan manhattan mobility model[4]. Dalam pergerakan random Dibawah ini adalah contoh pembuatan pergerakan node.

./setdest $-\mathrm{v}<$ version of setdest>-n <num_of_nodes $>-p<$ pausetime $>-M<m a x s p e e d>-t$

$<$ simtime $>-\mathrm{x}\langle\operatorname{maxx}>-\mathrm{y}<\operatorname{maxy}>>$ namafile

waypoint model sudah disediakan dalam module ns 2, yang ada pada direktori " $n$ ns/indep-utils/cmu-scengen/setdest/[13]". Module tersebut tidak bisa langsung digunakan karena harus di install terlebih dahulu. cara installasi module tersebut lewat terminal. Setelah proses installasi barulah module tersebut bisa digunakan, berikut cara penggunaan module random waypoint model di setdest[14].

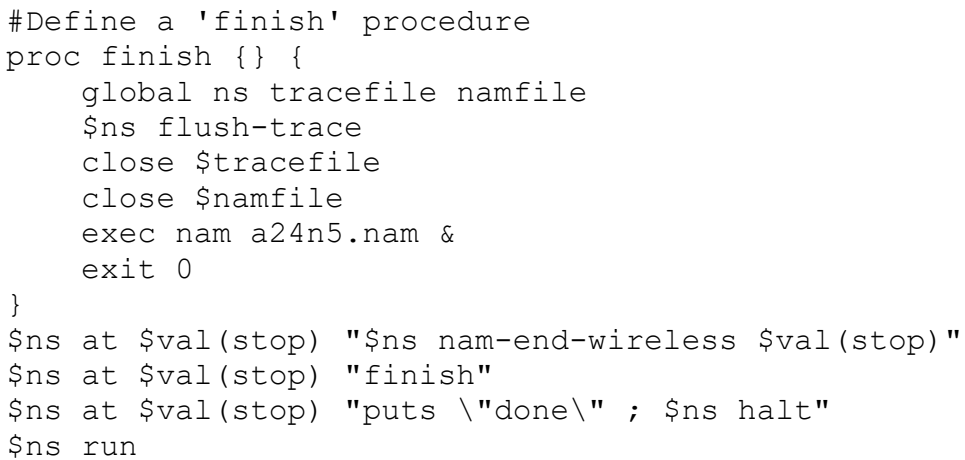

Sebagai proses untuk mengakhiri program simulasi yang dibuat, berikut adalah script yang digunakan.

Simulasi Data Pada simulasi data skenario yang dibuat menjalankannya adalah dengan ns 2 tadi. Dimana untuk melakukan simulasi data tersebut dibutuhkan sebuah pola trafik[15], skenario pergerakan dan script tcl. Untuk menjalankan file tcl tersebut, pertama masuk direktori file tcl disimpan melalui terminal[10]. Kemudiam ketikan perintah "\$ns < spasi> namafile.tcl"

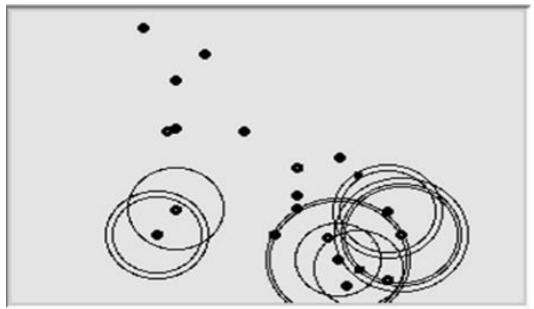

Gambar 2. Simulasi ns 2 dengan node

\section{HASIL DAN PEMBAHASAN}

Pada bagian ini akan dijelaskan hasil uji coba dari skenario yang telah dirancang pada untuk mendukung penelitain kami. Hasil uji coba ini akan memberikan gambaran terhadap performa dari protokol routing yang diusulkan pada jaringan MANET.

a. Packet delivery ratio (PDR) adalah rasio antara banyaknya paket yang diterima oleh tujuan dengan banyaknya paket yang dikirim oleh sumber.

b. End to End Delay adalah rata-rata waktu yang dibutuhkan oleh paket data untuk tiba ditempat tujuan yang mana mencakup keterlambatan yang disebabkan oleh penemuan rute dan antrian transmisi paket data.

c. Normalized routing load merupakan rasio antara jumlah paket routing dengan paket data yang berhasil dikirim

d. PSO adalah algortima optimasisasi untuk mendapatakan nilai yg tepat. 
JURNAL MEDIA INFORMATIKA BUDIDARMA

Volume 5, Nomor 2, April 2021, Page 468-474

ISSN 2614-5278 (media cetak), ISSN 2548-8368 (media online)

Available Online at https://ejurnal.stmik-budidarma.ac.id/index.php/mib

DOI 10.30865/mib.v5i2.2636

Dibawah ini adalah susunan algoritma yang sudah di kerjakan hingga memunculkan nilai dan hasil dar pengujian parameter-parameter yang ada serta di optimasisasi mengunakan algoritma PSO.untuk menemukan hasil yang terbaik.

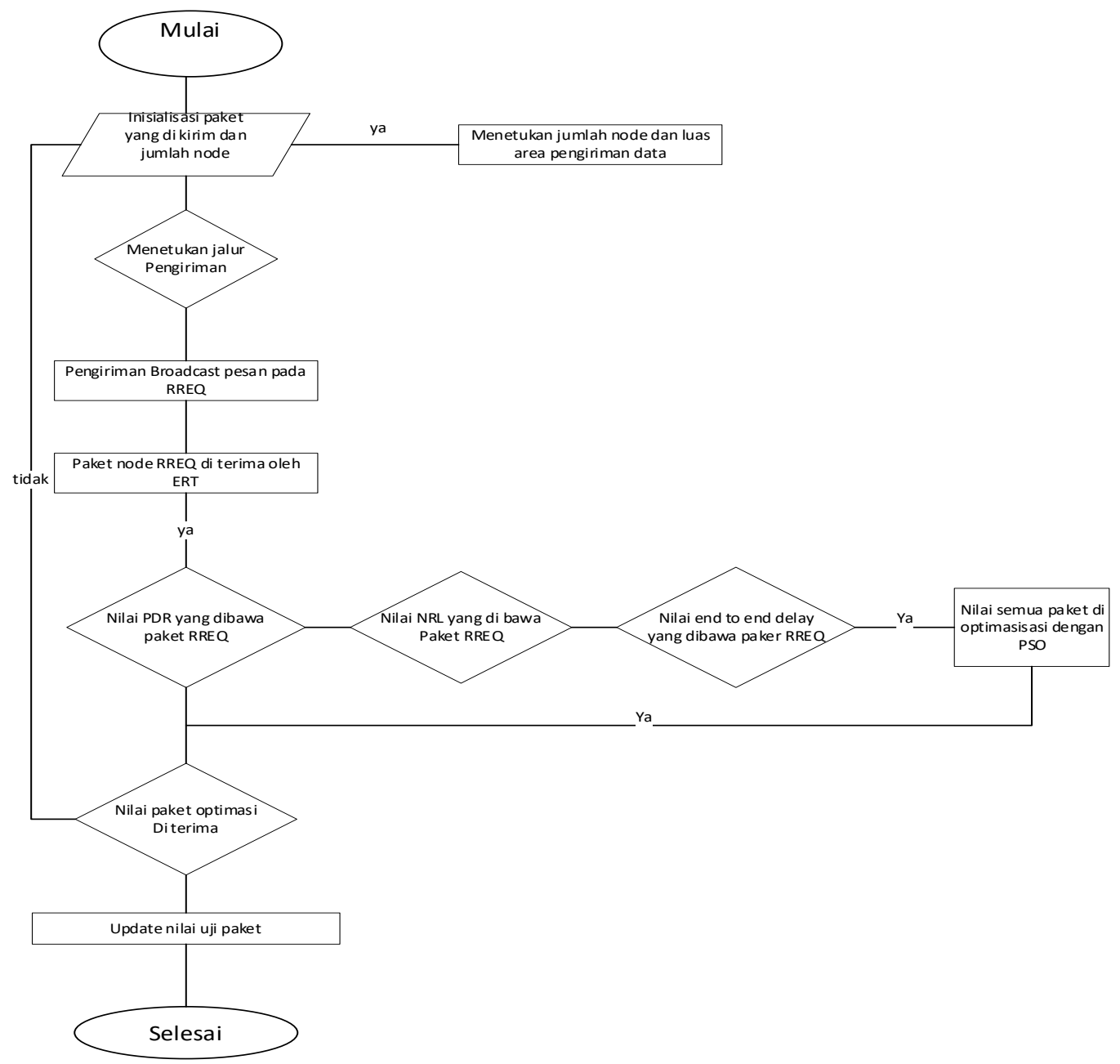

Gambar 3. Flowchart pengujian

Dari ketiga parameter yang ada kemudian dihitung dari perbandingan jenis trafik dan juga dilakukan optimasisasi mengunakan algoritma PSO yang berdasarkan jumlah node, waktu simulasi dan luas area. Perbandingan antara jenis trafik yaitu tcp dan udp lalu dengan waktu simulasi $200 \mathrm{sec}$ dan luas area $1000 \mathrm{~m}^{2} \mathrm{x}$

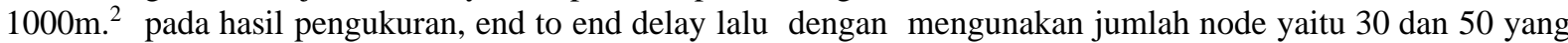
berlangsung dalam simulasi. Pada simulasi ini adanya penurunan nilai delay pada setip simulasi node uji cobal Hal tersebut terjadi karena pada adanya update tabel rute secara periodik, sehingga paket data harus menunggu lama untuk menemukan rute ke tujuan.tetapi berbeda kebalikan dengan banyak nya node maka adanya perubahan yang secara dinamis dapat menemukan rute tersendiri.pada tabel di bawah berikut juga dapat di lihat Nilai optimasisasi mengunakan pso juga yang menurutkan nilai delay menjadi lebih kecil.

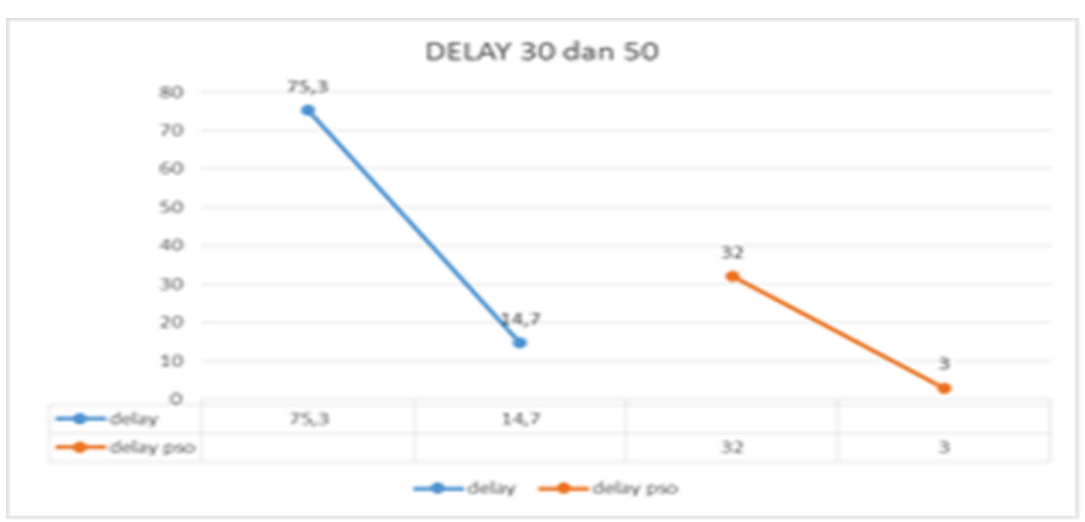

Gambar 4. Grafik dari perhitungan delay

Alon Jala Tirta Segara, Copyright (C2021, MIB, Page 472 
Dari grafik dibawah ini dapat dilihat terjadi naiknya nilai hitung parameter paket delivery ratio pada setiap node uji coba dan juga kenaikan nilai tersebut sangat lah signifikan dari nilai awal 81,5\% pada node 31 dan $96,1 \%$ pada node 50. hal ini terjadi karena jumlah node yang mempengaruhi route pegiriman data lalu pada setiap node kami melakukan optimasisasi dan perubahan nilai dari kedua simulasi untuk PDR dapat kami maksimalkan dengan sumber trafik yang berbeda setalah kami melakukan optimasisasi mengunakan PSO dan pada hasil optimasisasi ini pada setiap node simulasi nilai meningakat menyentuh angka $98,1 \%$ pada node 50 dan $89,2 \%$ pada node 30 .

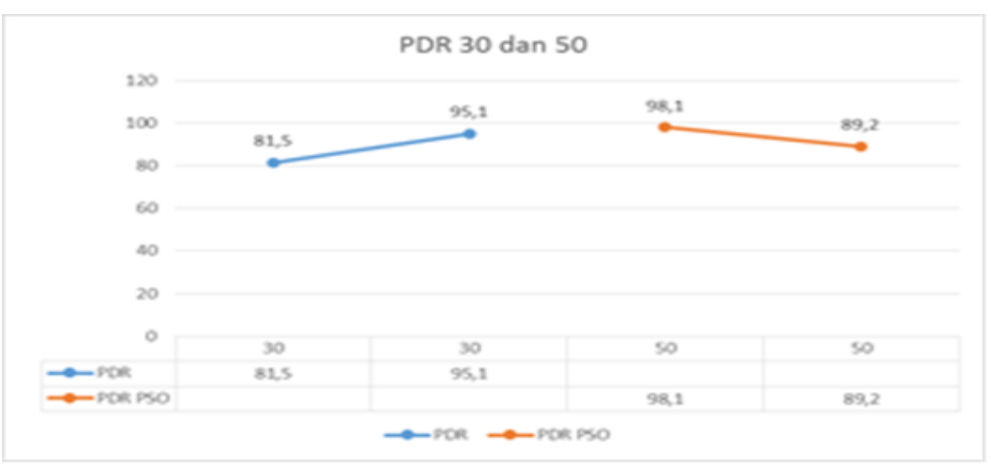

Gambar 5. Grafik dari perhitungan PDR

Pada grafik NRL terjadi kenaikan nilai NRL pada dari node 30 dengan nilai $12,7 \%$ dan node 50 dengan nilai $51,4 \%$ Jadi, faktor utama yang mempengaruhi rendahnya nilai NRL adalah penggunaan jenis trafik yang memiliki sifat oriented conection dan variasi kecepatan node yang semakin tinggi. Dengan adanya nilai NRL yang rendah maka kinerja protokol semakin efisien dan sifat dari topologi relatif stabil.lalu untuk .nilai optimasisasi mengunakan PSO dapat dilihat pada nilai setiap node 30 dan juga 50 terjadi kenaikan secara signifikan dengan nilai pada node 30 adalah $13,1 \%$ dan node 50 adalah $51,4 \%$.

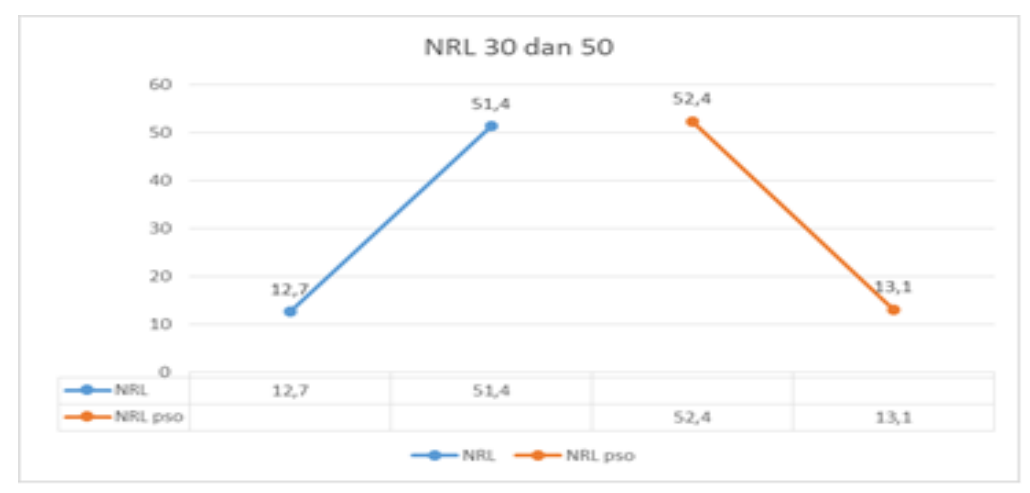

Gambar 6. Grafik dari perhitungan NRL dengan node

\section{KESIMPULAN}

Setelah melakukan simulasi dan melihat nilai-nilai perbandingan yang ada maka kami peroleh suatu kesimpulan mengenai Dari hasil uji coba parameter di atas didapatkan nilai rata-rata PDR pada node 50 95,1 dan node 30 $81,5 \%$, nilai NRL pada node $5051,4 \%$ dan node $3012,7 \%$. Sementara parameter Sedangkan pada pengukuran parameter Average Delay pada node 30 didapatkan hasil yang semakin menurun akibat dari variasi kecepatan node, dibandingkan node 50 yang memiliki nilai naik turun. protokol AOMDV merupakan protokol reactive yang memiliki keunggulan dapat menciptakan beberapa rute dalam pengiriman paket dan dapat melakukan backup rute yang bertujuan untuk mengatasi adanya kegagalan paket yang terkirim. Sifat reactive protokol AOMDV dapat mengatasi resiko naik turunnya nilai dari parameter uji PDR, NRL, Average Delay.lalu pada hasil optimasisasi PSO yang di gunakan di dapat kan hasil yg optimal pada setiap nilai parameter yang di uji cobakan nilai setiap parameter terjadi pada kenaikan yang signifikan pada nilai parameter PDR dan NRL sedangkan untuk nilai Avaerage delay terjadi penurunan pada setiap nilai simulasi.

\section{UCAPAN TERIMAKASIH}

Terima kasih kami kepada pihak-pihak yang telah mendukung terlaksananya penelitian ini secara teknis maupun dengan non teknis. 
JURNAL MEDIA INFORMATIKA BUDIDARMA

Volume 5, Nomor 2, April 2021, Page 468-474

ISSN 2614-5278 (media cetak), ISSN 2548-8368 (media online)

Available Online at https://ejurnal.stmik-budidarma.ac.id/index.php/mib

DOI 10.30865/mib.v5i2.2636

\section{REFERENCES}

[1] M. Manjunath and D. H. Manjaiah, "Comparative Study of AODV, SAODV, DSDV and AOMDV Routing Protocols in MANET Using NS2,” Int. J. Commun. Netw. Syst., vol. 004, no. 001, pp. 18-22, 2015, doi: 10.20894/ijcnes.103.004.001.005.

[2] S. Buta, S. Baghla, and H. Monga, "Mobility models based performance evaluation of AOMDV routing protocol of MANET," Intern. ional J. Appl. Res., vol. 3, no. 1, pp. 82-86, 2017.

[3] N. Saravanan, A. Subramani, and P. Balamurugan, "Optimal route selection in MANET based on particle swarm optimization utilizing expected transmission count," Cluster Comput., vol. 22, no. s5, pp. 11647-11658, 2019, doi: 10.1007/s10586-017-1445-8

[4] B. K. Rao and A. S. N. Chakravarthy, "Optimized AODV Routing Algorithm in MANET for Maximizing the Network Lifetime," no. 2, pp. 4054-4059, 2019, doi: 10.35940/ijrte.B3457.078219.

[5] A. K. Yadav and A. Kush, "TCP- and UDP-based performance evaluation of AODV and DSR routing protocol on varying speed and pause time in mobile ad hoc networks," Adv. Intell. Syst. Comput., vol. 638, pp. 323-332, 2018, doi: 10.1007/978-981-10-6005-2_34.

[6] R. Wulandari, “ANALISIS QoS (QUALITY OF SERVICE) PADA JARINGAN INTERNET (STUDI KASUS : UPT LOKA UJI TEKNIK PENAMBANGAN JAMPANG KULON - LIPI),” J. Tek. Inform. dan Sist. Inf., vol. 2, no. 2, pp. 162-172, 2016, doi: 10.28932/jutisi.v2i2.454.

[7] R. Shaikh and M. Sasikumar, "Available Online at www.ijarcs.info International Journal of Advanced Research in Computer Science," Procedia Comput. Sci., vol. 45, no. C, pp. 493-498, 2015.

[8] A. Wong Yoon Khang et al., "Qualitative-based QoS performance study using hybrid ACO and PSO algorithm routing in MANET," J. Phys. Conf. Ser., vol. 1502, no. 1, 2020, doi: 10.1088/1742-6596/1502/1/012004.

[9] T. H. Sureshbhai, M. Mahajan, and M. K. Rai, "An Investigational Analysis of DSDV, AODV and DSR Routing Protocols in Mobile Ad Hoc Networks," 2018 Int. Conf. Intell. Circuits Syst., pp. 281-285, 2018, doi: 10.1109/ICICS.2018.00064.

[10] B. M. Susanto, A. Hariyanto, and Surateno, "Performance comparison of proactive and reactive routing protocol in mobile ad hoc network," J. Commun., vol. 13, no. 5, pp. 218-224, 2018, doi: 10.12720/jcm.13.5.218-224.

[11] A. A. Antony and B. Thomas, "A Study on Packet Loss Reduction methods and Node Registration methods in AODV for MANET A Study on Packet Loss Reduction methods and Node Registration methods in AODV for MANET," 2018, doi: 10.1088/1757-899X/396/1/012032.

[12] S. Murugan, S. Jeyalaksshmi, B. Mahalakshmi, G. Suseendran, T. Nusrat Jabeen, and R. Manikandan, "Comparison of aco and pso algorithm using energy consumption and load balancing in emerging manet and vanet infrastructure," J. Crit. Rev., vol. 7, no. 9, pp. 1197-1204, 2020, doi: 10.31838/jcr.07.09.219.

[13] P. Li, L. Guo, and F. Wang, "A Multipath Routing Protocol with Load Balancing and Energy Constraining Based on AOMDV in Ad Hoc Network," Mob. Networks Appl., 2019, doi: 10.1007/s11036-019-01295-7.

[14] A. A. Antony and B. Thomas, "A Study on Packet Loss Reduction methods and Node Registration methods in AODV for MANET," IOP Conf. Ser. Mater. Sci. Eng., vol. 396, no. 1, pp. 0-8, 2018, doi: 10.1088/1757-899X/396/1/012032.

[15] P. R. Satav and P. M. Jawandhiya, "An Energy Efficient Route Selection in MANET with AOMDV Routing Algorithm," Proc. 2018 3rd IEEE Int. Conf. Res. Intell. Comput. Eng. RICE 2018, vol. 1, pp. 5-9, 2018, doi: 10.1109/RICE.2018.8509047. 